\title{
SUPERFÍCIES ESTRIADAS EM ARENITOS DO GRUPO ITARARÉ PRODUZIDAS POR GELO FLUTUANTE, SUDESTE DO ESTADO DO PARANÁ
}

\author{
FERNANDO FARIAS VESELY ${ }^{1} \&$ MARIO LUIS ASSINE ${ }^{2}$
}

\begin{abstract}
SOFT-SAND STRIATED SURFACES PRODUCED BY FLOATING ICE, PERMOCARBONIFEROUS ITARARE GROUP, BRAZIL Permocarboniferous glacial pavements has already been found in several places in southern Brazil. In the southeast of Parana State there are many occurrences, as the well-known striated surface produced over Devonian basement rocks in the locality of Witmarsun. However, most of the pavements are in fact soft-sediment striated surfaces preserved in the lower part of the glacial Itarare Group itself. At the base of a deglacial sequence exposed in the valley of the Salto River near the Palmeira town, several soft-sand striated surfaces are distributed in four different stratigraphic levels inside cross-stratified sandstones interpreted as deposits of subaqueous outwash fans. Scour marks indicate paleoglacial movement towards the azimuth $341^{\circ}$, coherent with the advance of glaciers postulated in regional paleogeographic reconstructions for Permocarboniferous of south Brazil. The surfaces are discontinuous, sometimes slightly concave and associated with linear grooves, and the preservation was favored by thin laminae of fines. These characteristics and the fact that they are not covered by coarse facies like diamictites, allow us to interpret them as soft-sand striated surfaces produced by floating ice. The highly consistent orientation of striations and grooves suggests that they were formed near the grounding zone of an ice shelf in a marine environment, but the surfaces could be ice keel scour marks produced by free-floating ice masses.
\end{abstract}

Keywords: glacial pavements, soft-sediment striated surfaces, Permocarboniferous, Parana Basin

\begin{abstract}
Resumo Um dos principais sítios de ocorrência de estrias glaciais permocarboníferas no Brasil encontra-se no sudeste do Estado do Paraná. Nesta área, muitas das superfícies estriadas ocorrem em estratos carboníferos do próprio Grupo Itararé, constituindo exemplo de estrias formadas sobre sedimentos moles ou inconsolidados. No vale do rio do Salto, Município de Palmeira, algumas estrias anteriormente descritas como pertencentes à Formação Furnas, estão na verdade sobre arenitos médios a grossos da parte inferior do Grupo Itararé, interpretados como depósitos de leques subaquosos de degelo. As superfícies estriadas são descontínuas, algumas vezes côncavas e com bermas marginais, sendo recorrentes na vertical uma vez que foram constatadas em pelo menos quatro níveis estratigráficos diferentes numa seção de aproximadamente $10 \mathrm{~m}$ de espessura. Marcas de objetos e sulcos lineares indicam paleofluxo glacial para o azimute $341^{\circ}$, compatível com as paleocorrentes medidas nos arenitos e com o sentido regional de avanço das geleiras no sul do Brasil. Pelas suas caracteristicas, as superfícies estriadas são interpretadas com o produto de abrasão glacial por gelo flutuante. A constância nas direções sugere origem relacionada à abrasão da base de plataformas de gelo flutuante, além da zona de aterramento, mas também foi considerada a hipótese de serem as estrias e os sulcos produto de abrasão por quilhas de icebergs.
\end{abstract}

Palavras-chaves: pavimentos glaciais, superfícies estriadas, Permocarbonífero, Grupo Itararé, Bacia do Paraná

INTRODUÇÃO A descoberta das primeiras superfícies estriadas de origem glacial, relacionadas à glaciação permocarbonífera que afetou a atual região sul do Brasil, foi noticiada simultanemente por Barbosa (1940) e Carvalho (1940). Desde então, diversas outras ocorrências foram encontradas, tanto em rochas do embasamento do Grupo Itararé, quanto em rochas permocarboniferas (Tabela 1).

Superfícies estriadas são comumente interpretadas como produto de abrasão subglacial sobre substratos rígidos, produzida na rocha subjacente pelo atrito dos clastos transportados na base das geleiras. Este processo foi responsável pela geração de estrias glaciais em rochas pré-carboníferas do embasamento do Grupo Itararé, como é o caso das superfícies estriadas em rochas metamórficas e magmáticas pré-cambrianas, ou ainda, em rochas sedimentares de sequiências mais antigas, como é o caso de estrias sobre arenitos devonianos da Formação Furnas. O processo também explica satisfatoriamente a origem de estrias em pavimentos de clastos (seixos a matacões) dentro do próprio Grupo Itararé,

I - UNESP - Curso de Pós-graduação em Geociências - Rio Claro-SP - Endereço atual: UFPR - Pós-Gaduação em Geologia, Curitiba-PR - E-mail: fernandovesely@hotmail.com

2 - UNESP - Departamento de Geologia Aplicada - Rio Claro-SP - E-mail: assine@1c.unesp.br 
Tabela 1 - Principais ocorrências de superficies estriadas na Bacia do Paraná

\begin{tabular}{|c|c|c|c|c|c|}
\hline \multicolumn{6}{|c|}{ SUPERFÍCIES ESTRIADAS EM ROCHAS PRÉ-CARBONIFFERAS } \\
\hline & FONTE & DESCRICÁO & \multicolumn{2}{|c|}{ LOCALIZAÇÃO } & PALEORLUXO \\
\hline 1 & Barbosa (1940) & $\begin{array}{l}\text { Estrias sobre o embisamento } \\
\text { pre-cimbriano }\end{array}$ & \begin{tabular}{|l|}
$\begin{array}{l}\text { São Bento } \\
\text { do Sul }\end{array}$ \\
\end{tabular} & $\mathrm{SC}$ & $335^{\circ}$ \\
\hline 2 & Almeida (1948) & $\begin{array}{l}\text { Estrias em rochas montommée do } \\
\text { embasumento pré-cianbriano }\end{array}$ & Salto & $\mathrm{SP}$ & $335^{\circ}$ \\
\hline 3 & Bigarellia ef al. (1967) & $\begin{array}{l}\text { Estrias sobic arenitos dia } \\
\text { Formaçĩo Furnas }\end{array}$ & Patherira & PR & $358^{\circ \prime}$ \\
\hline 4 & $\begin{array}{l}\text { Rochis-Canpos et al } \\
\text { (1988) }\end{array}$ & $\begin{array}{l}\text { Estrias sobre o embasamento } \\
\text { pré-cumbriano }\end{array}$ & \begin{tabular}{|l|} 
Alfredo \\
Wignerer \\
\end{tabular} & SC & $327^{\circ}$ \\
\hline \multicolumn{6}{|c|}{ SUPERFICIES ESTRIADAS EM ROCHAS DO GRUPO ITARARÉ } \\
\hline & FONTE & DISSCRIÇño & \multicolumn{2}{|c|}{ LOCALIZAÇヘ̃OO } & PALEOFLUXO \\
\hline 5 & $\begin{array}{l}\text { Rochia-Ciampos et al. } \\
\text { (1976) }\end{array}$ & $\begin{array}{l}\text { Estrias em pavimento } \\
\text { de clastos }\end{array}$ & Capivarti & SP & $323^{\mathrm{a}}$ \\
\hline 6 & $\begin{array}{l}\text { Tomizzelli \& Soliani } \\
\text { (1982) }\end{array}$ & $\begin{array}{l}\text { Estrias en arenitos } \\
\text { conglomeráticos }\end{array}$ & $\begin{array}{l}\text { Cachocira } \\
\text { do Sul }\end{array}$ & RS & $360^{\prime \prime}$ \\
\hline 7 & $\begin{array}{l}\text { Tomazelli \& Soliani } \\
\text { (1982) }\end{array}$ & $\begin{array}{l}\text { Estrials e sulcos em } \\
\text { diamictitos }\end{array}$ & \begin{tabular}{|l|} 
Pinhleiro \\
Machado \\
\end{tabular} & RS & $15^{\circ}$ \\
\hline 8 & $\begin{array}{l}\text { Calelimo-Chang ol ol. } \\
\text { (1990) }\end{array}$ & $\begin{array}{l}\text { Estrias e sulcos em } \\
\text { diamictitos }\end{array}$ & Ltararé & SP & $330^{\circ}$ \\
\hline 9 & Santos el al. (1992) & $\begin{array}{l}\text { Estruturas de arrasto } \\
\text { de icebergx cm ritmitos }\end{array}$ & $\begin{array}{l}\text { Trombudo } \\
\text { Central } \\
\end{array}$ & $\mathrm{SC}$ & $295^{\circ}$ \\
\hline 10 & Gesicki ef al. (1996) & $\begin{array}{l}\text { Estrias e sulcos em } \\
\text { arenitos e diamictitos }\end{array}$ & Rio Estrela & MS & $332^{\circ}$ \\
\hline 11 & Gesicki ef al. (1996) & $\begin{array}{l}\text { Estrias e sulcos em } \\
\text { arenitos e diamichitos }\end{array}$ & Cipolîndia & MS & $335^{\circ}$ \\
\hline 12 & $\begin{array}{l}\text { Riccomini \& Velizquez } \\
\text { (1999) }\end{array}$ & Estrias em arenitos & Paraguai & & $35^{\circ}$ \\
\hline
\end{tabular}

como a ocorrência em Capivari (SP) descrita por Rocha-Campos et al. (1976).

Muitas superfícies estriadas ocorrem, entretanto, em diamictitos, ritmitos e arenitos do próprio Grupo Itararé (ocorrências 6 a 12 na tabela 1), tendo sido geradas no sítio deposicional sobre sedimentos moles ou inconsolidados (soft-sediment striated surfaces). Tais tipos de superfícies estriadas ocorrem também nos estratos permocarboníferos do Grupo Dwyka da Bacia Karoo na África do Sul (Savage 1972, Visser 1990) e em muitas sequiências glaciais antigas (Woodworth-Lynas \& Dowdeswell 1994).

A faixa de afloramentos do Grupo Itararé no sudeste do Estado do Paraná é particularmente interessante para o estudo de pavimentos glaciais produzidos sobre substratos moles. A área que apresenta a maior concentração de estrias deste tipo é a da Folha Quero-Quero mapeada por Fuck et al. (1966), fato já destacado no trabalho de Bigarella et al (1967).

Dentre as várias ocorrências na área destacam-se, pelo grau de preservação e recorrência em diversos níveis estratigráficos, as do no vale do rio do Salto no Município de Palmeira (Fig. 1), cuja descrição e interpretação são objetivos deste trabalho.

CONTEXTOESTRATIGRÁFICO Os pavimentos glaciais estudados ocorrem em estratos da parte inferior do Grupo Itararé, que no sudeste do Estado do Paraná repousa em discordância angular sobre os estratos devonianos da Formação Furnas (Assine 1996). O intervalo analisado pertence à Formação Campo do Tenente conforme proposta de Schneider et al. (1974), mas corresponde, em subsuperfície, com a seção denominada Membro Tarabaí da Formação Lagoa Azul de França \& Potter (1988).

Considerando ser um intervalo contíguo aos diamictitos e ritmitos sotopostos aos arenitos do trato Lapa/Vila Velha, que segundo França et al. (1996) estão na base da Formação Campo Mourão, a seção analisada é de idade neocarbonífera (Fig. 2).

A sucessão vertical de fácies onde ocorrem os pavimentos glaciais está ilustrada na figura 3 . Superpostos aos diamictitos da base (Fig. 4A) ocorrem diversos corpos de arenitos amalgamados, com um a dois metros de espessura, entremeados aos quais se encontram as superfícies estriadas, localmente com sulcos. Os

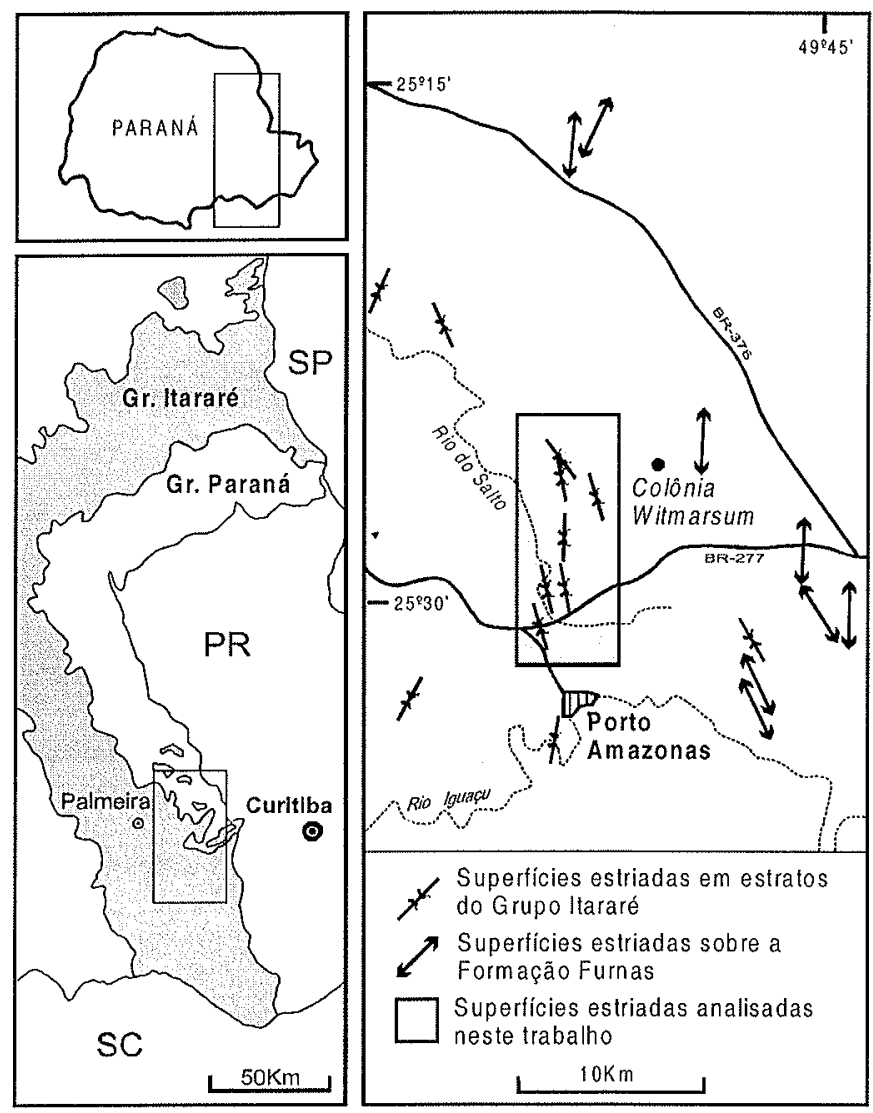

Figura 1 - Localização da área estudada com indicação das diversas ocorrências de estrias glaciais na região (modificado de Bigarella et al. 1967).

arenitos são médios a grossos, com estratificação cruzada planar e/ou acanalada (fácies $\mathrm{St} / \mathrm{Sp}$ ) e definem um pacote contínuo com cerca de $15 \mathrm{~m}$ de espessura. Localmente a estratificação contem convoluções restritas aos sets em que se manifestam e retratam deformação penecontemporânea à sedimentação.

Ritmitos síltico-argilosos com clastos caídos (fácies Fld, Fig. 4B) cobrem os arenitos, evidenciando a presença de gelo flutuante. Intercalados aos ritmitos, existem diamictitos maciços com matriz argilosa, alguns com estratificação incipiente, fácies estas que podem ser observadas no entrocamento para Porto Amazonas. $\mathrm{Na}$ estrada para esta cidade, a $2 \mathrm{~km}$ do trevo, associados aos ritmitos, ocorrem também camadas centimétricas a deciméticas de arenitos com gradação normal (turbiditos).

CARACTERÍSTICAS DOS PAVIMENTOS GLACIAIS Os pavimentos glaciais expostos no vale do rio do Salto ocorrem em arenitos do Grupo Itararé, embora a seção tenha sido inicialmente incluída na faixa de ocorrência da Formação Furnas no mapa geológico de Fuck et al. (1966).

Superfícies estriadas em três níveis estratigráficos diferentes, nos limites de corpos de arenitos com estratificação cruzada, equiidistantes entre si de um a dois metros (Fig. 5), ocorrem na margem esquerda do rio do Salto, na área de domínio da rodovia BR-277, a 200 metros do entroncamento da estrada de acesso a Porto Amazonas. A ocorrência foi citada pela primeira vez por Canuto (1985), que não a considerou de origem glacial. Posterior- 
mente, Vesely \& Assine $(1998,1999)$ e Rocha-Campos et al. (1999) noticiaram a existência das estrias assumindo a ação de geleiras em diferentes contextos deposicionais.

As estrias são retilíneas e contínuas, com largura e profundidade de alguns milímetros a poucos centímetros. Na maioria das vezes, as superfícies que contém estrias são lateralmente descontínuas, delineando perfil transversal côncavo, em alguns casos com bermas marginais.

Superfícies estriadas semelhantes, entremeadas em camadas de arenitos com estratificação cruzada, ocorrem também na margem direita do rio, a cerca de um quilômetro a norte da rodovia, onde foram constatados quatro níveis estratigráficos distintos portadores de estrias glaciais (Fig. 6A/B). Feições de escorregamento foram observadas em algumas superfícies estriadas, constituindo característica diagnóstica de que foram geradas sobre substrato mole, ou seja, sobre areias ainda inconsolidadas dentro do sítio deposicional (Fig. 6C). Para efeito de comparação, na figura 6D é apresentado um exemplo clássico de feição de escorregamento associados a estrias presentes em arenitos permocarboníferos do Grupo Dwyka da África do Sul, discutidas inicialmente por Savage (1972)

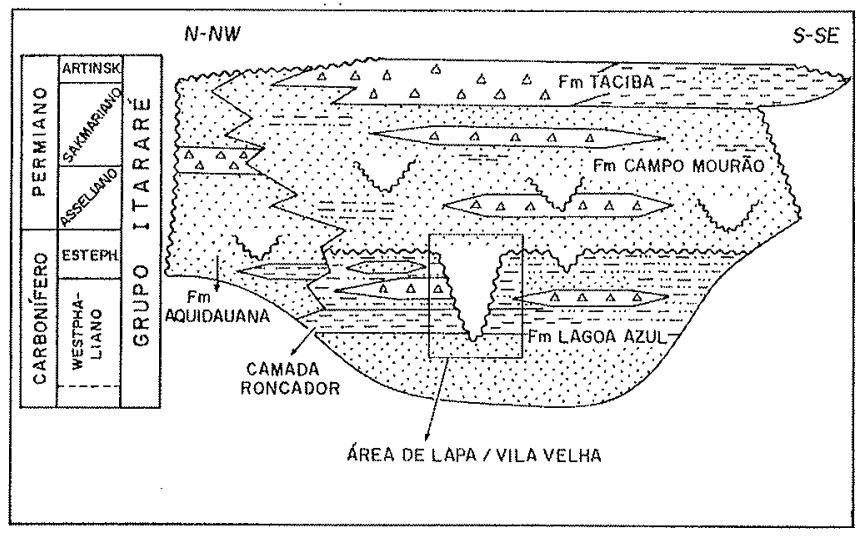

Figura 2 - Carta estrafigráfica simplificada do Grupo Itararé, com destaque para a posição estratigráfica dos arenitos Lapa / Vila Velha (França et al. 1996).

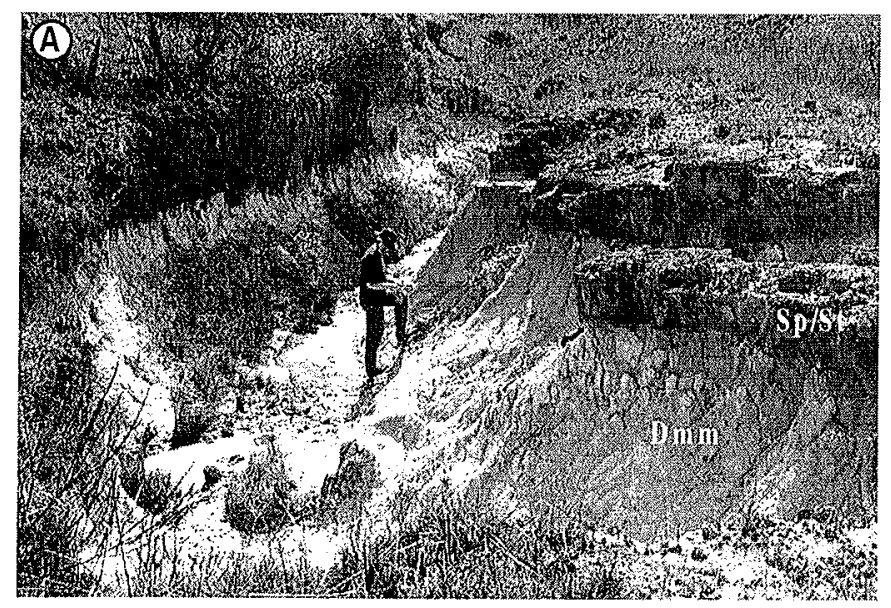

Também podem ocorrer sulcos retilíneos isolados com mais de $20 \mathrm{~m}$ de comprimento, largura de até $20 \mathrm{~cm}$ e profundidade de até $10 \mathrm{~cm}$. Os sulcos são também descontínuos e podem apresentar variações de largura e profundidade.

Medidas de direção das estrias e dos sulcos em todos os pavimentos resultou no azimute médio $341^{\circ}$, semelhante aos valores obtidos por Bigarella et al. (1967) na região (azimute médio 358 ) e compatíveis com medidas de paleocorrentes efetuadas nos arenitos (Fig. 3). Sentido de fluxo glacial para NNW pôde ser determinado a partir da identificação de marcas de escavação de objetos, que

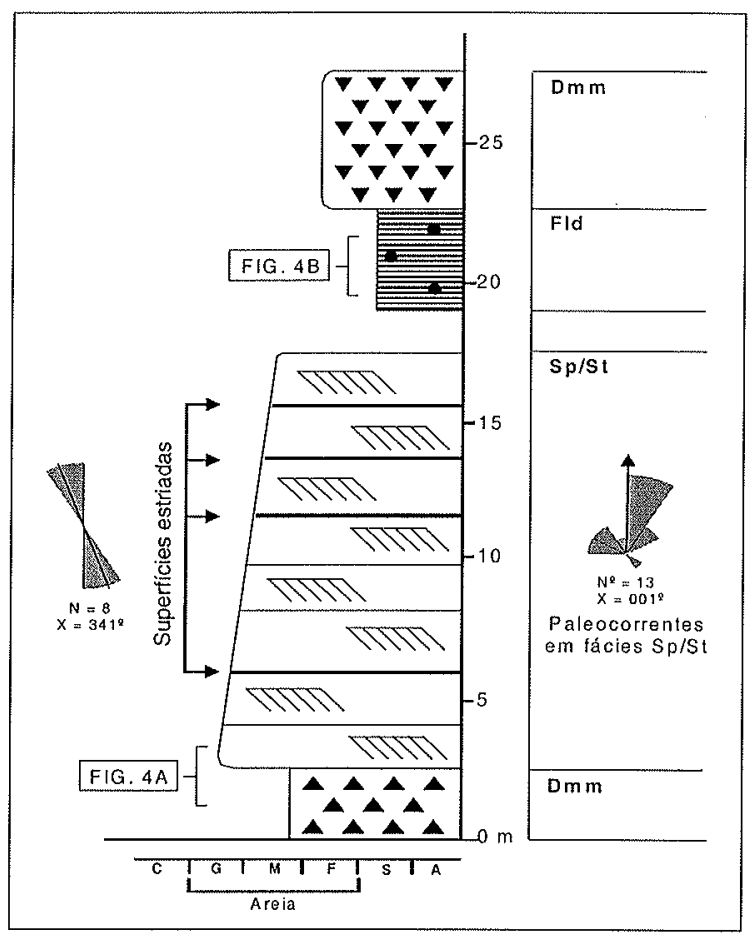

Figura 3 - Sucessão vertical de fácies no vale do rio do Salto. Setas indicam a localização dos pavimentos glaciais. $\mathrm{Dmm}=$ diamictito maciço; $\mathrm{Sp} / \mathrm{St}=$ arenito com estratificação cruzada planar/acanalada; Fld = finos laminados com clastos caídos.

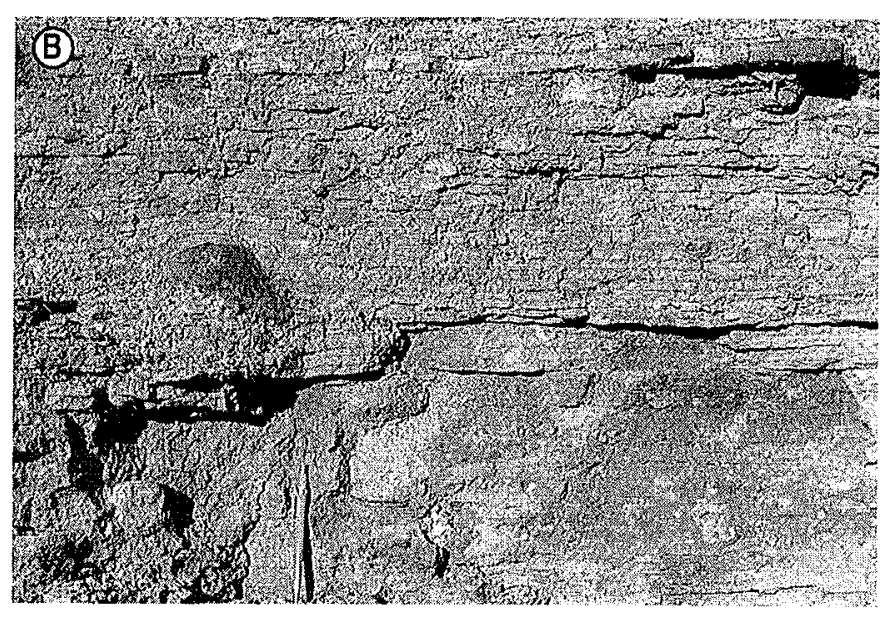

Figura 4-A) Tilito Cancela (fácies Dmm) coberto abruptamente pelos arenitos que contêm os pavimentos glaciais (fácies Sp/ St); B) ritmito com clasto caído de gelo flutuante. A localização das fotos no perfil levantado está indicada na figura 3. 

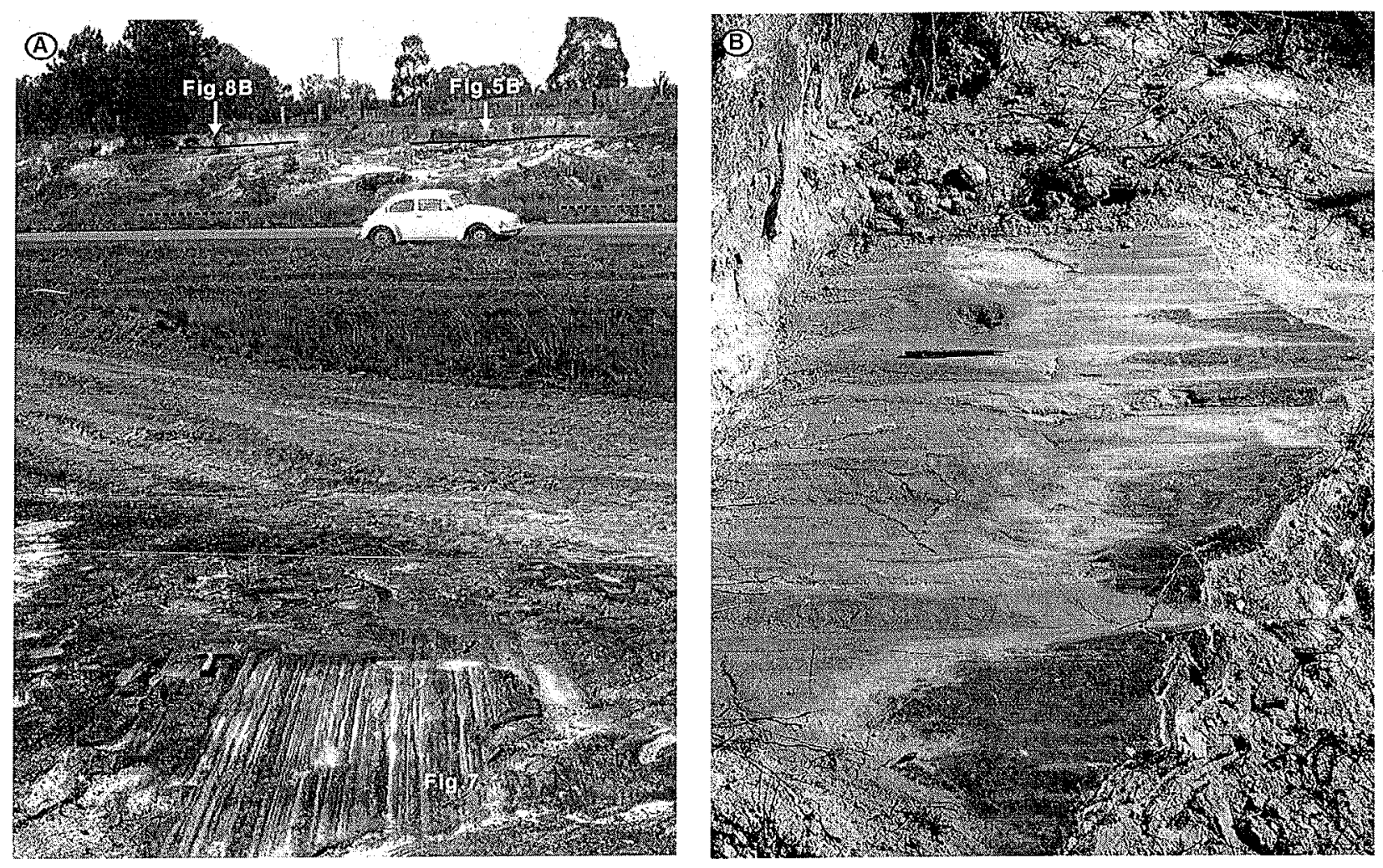

Figura 5 - Superficies estriadas na BR-277: A) panorama geral do afloramento, evidenciando em primeiro plano um nivel inferior com estrias e sulcos e ao fundo outros dois niveis distintos sobrepostos (indicados com traços pretos); B) detalhe da superficie do topo, onde se observam sulcos cobertos por lâmina de argila.
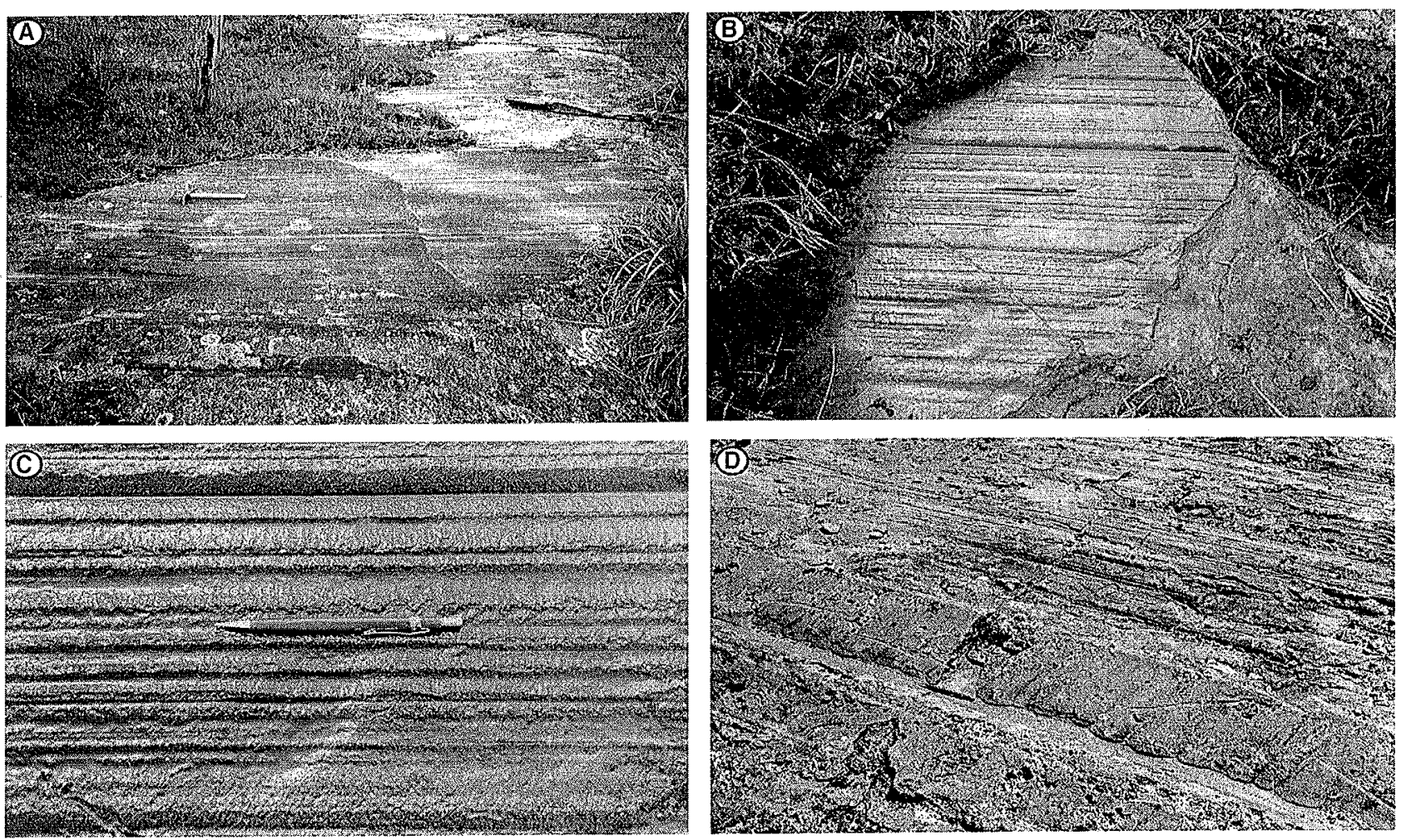

Figura 6 - A e B) vista geral de superficies estriadas na margem direita do rio do Salto; $C$ ) detalhe de B, mostrando feição de escorregamento lateral, perpendicular à estria; D) feição de escorregamento em arenitos do Grupo Dwyka.. 

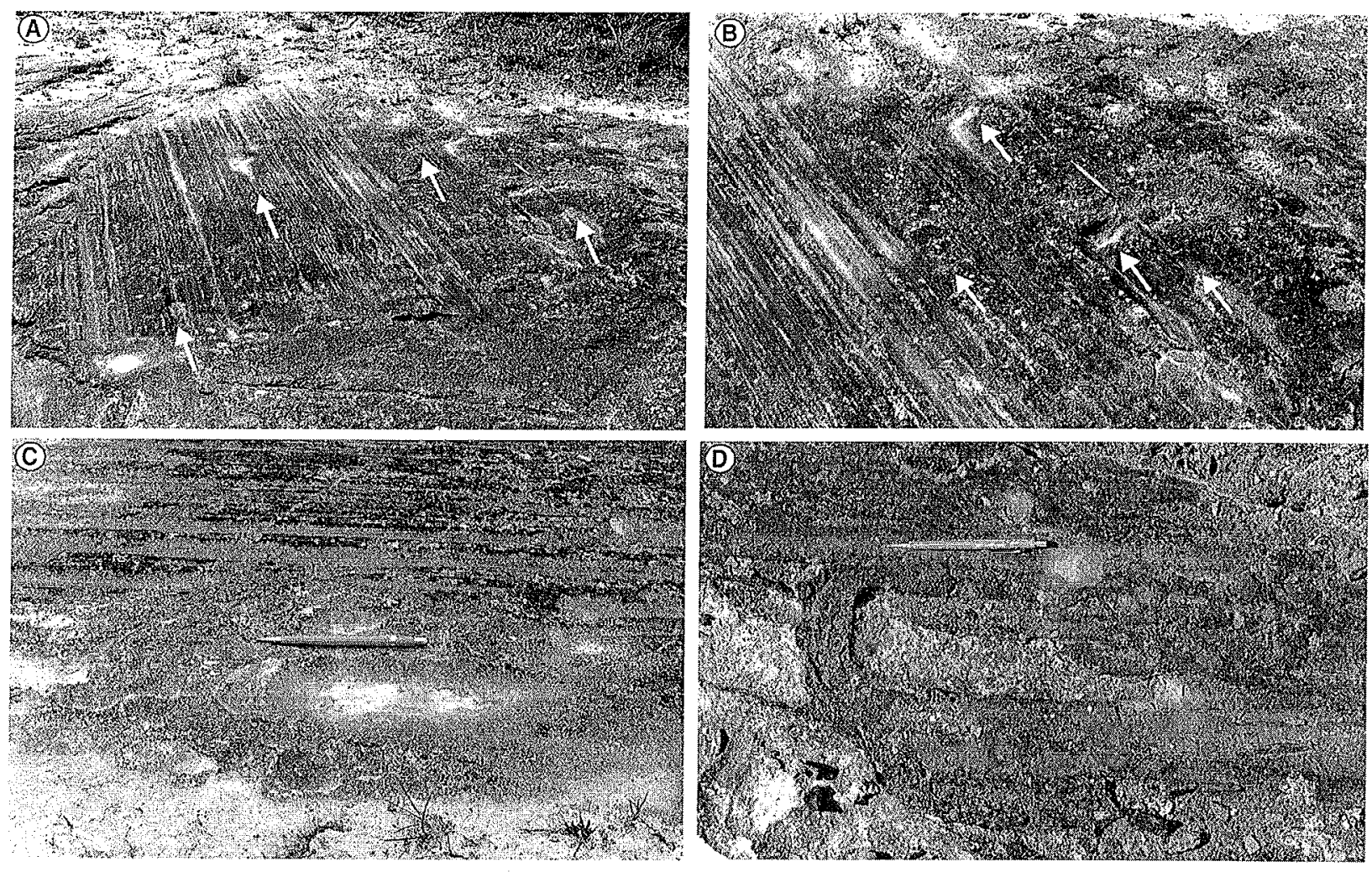

Figura 7-A e B) superfície estriada contendo marcas de escavação de objetos (indicados com setas); C) e D) detalhes das marcas, mostrando deformação sindeposicional nas suas terminações (esquerda) que apontam o sentido do movimento do gelo (da direita para a esquerda).

estão impressas sobre as superfícies estriadas e fora delas (Fig. 7).

GÊNESE DAS SUPERFÍCIES ESTRIADAS E DOS SULCOS

Feições de escorregamento, da crista em direção ao sulco das estrias (Fig. 6), constituem evidência conclusiva de que as superfícies foram formadas no sítio deposicional sobre substratos moles, mais especificamente sobre areias inconsolidadas (soft-sand striated surfaces). Corrobora esta interpretação o fato de haver deformação local dos estratos sotopostos às estrias.

A recorrência das superfícies na vertical indica que estas foram produzidas penecontemporaneamente à sedimentação dos arenitos, durante pelo menos quatro eventos de avanço de geleiras no sítio deposicional do Grupo Itararé. Mas, ao contrário da interpretação de que as estrias foram geradas por avanços de geleiras de base aterrada, como propõe Rocha-Campos et al. (1999), postula-se neste trabalho que as superfícies estriadas descritas nas margens do rio do Salto foram geradas em meio subaquoso devido à abrasão glacial por gelo flutuante.

Entre as evidências a favor da ação de gelo flutuante, destacase a descontinuidade lateral e a ausência de depósitos subglaciais acima dos pavimentos. Não foram encontrados também clastos associados às marcas de escavação, que podem ter sido produzidas pelo próprio atrito do gelo, na forma de quilhas e/ou fragmentos desagregados, sobre a superfície deposicional. A presença de pequenas bermas laterais em algumas superfícies é sugestiva do arraste de quilhas de gelo flutuante (ice-keels), conforme o modelo de Woodworth-Lynas \& Dowdeswell (1994) (Fig. 8A/B).

Sulcos isolados como o ilustrado na figura $8 \mathrm{C}$ não se coadunam com o modelo de geleira aterrada, onde a área de contato gelo/ superfície é lateralmente contínua e desenvolvem-se superfícies estriadas amplas e de topografia plana, tais como as descritas no Rio Grande do Sul por Tomazelli \& Soliani (1982)e na África do Sul por Visser et al. (1990).

A presença de lâminas de sedimentos síltico-argilosos sobre algumas das superfícies estriadas indica baixa energia do meio após a abrasão glacial, o que sugere a atuação de processos de decantação em meio subaquoso, o que teria contribuído para a preservação dos pavimentos glaciais.

Sulcos glaciais produzidos por gelo flutuante são comuns em fácies glácio-marinhas e glácio-lacustres do Quaternário, como demonstram os trabalhos de Weber (1958), Woodworth-Lynas \& Guigné (1990) e Dowdeswell et al. (1993). No registro geológico da Bacia do Paraná merece destaque a ocorrência de feições de escavação em ritmitos do Grupo Itararé no Estado de Santa Catarina descrita por Santos et al. (1992).

INTERPRETAÇÃO PALEOAMBIENTAL O padrão de variação textural na seção estudada é de granodecrescência ascendente, evidente no perfil estratigráfico vertical da figura 3. Fácies distais recobrem fácies proximais denotando empilhamento retrogradacional interpretado como uma sucessão de fácies de deglaciação (confome Visser 1997e Vesely 2001).

Na base da seção ocorrem diamictitos maciços síltico-arenosos de coloração avermelhada (fácies Dmm), pertencentes ao que Bigarella et al. (1967) denominaram Tilito Cancela. Trata-se de um corpo contínuo de tilitos subglaciais, com poucos metros de es- 

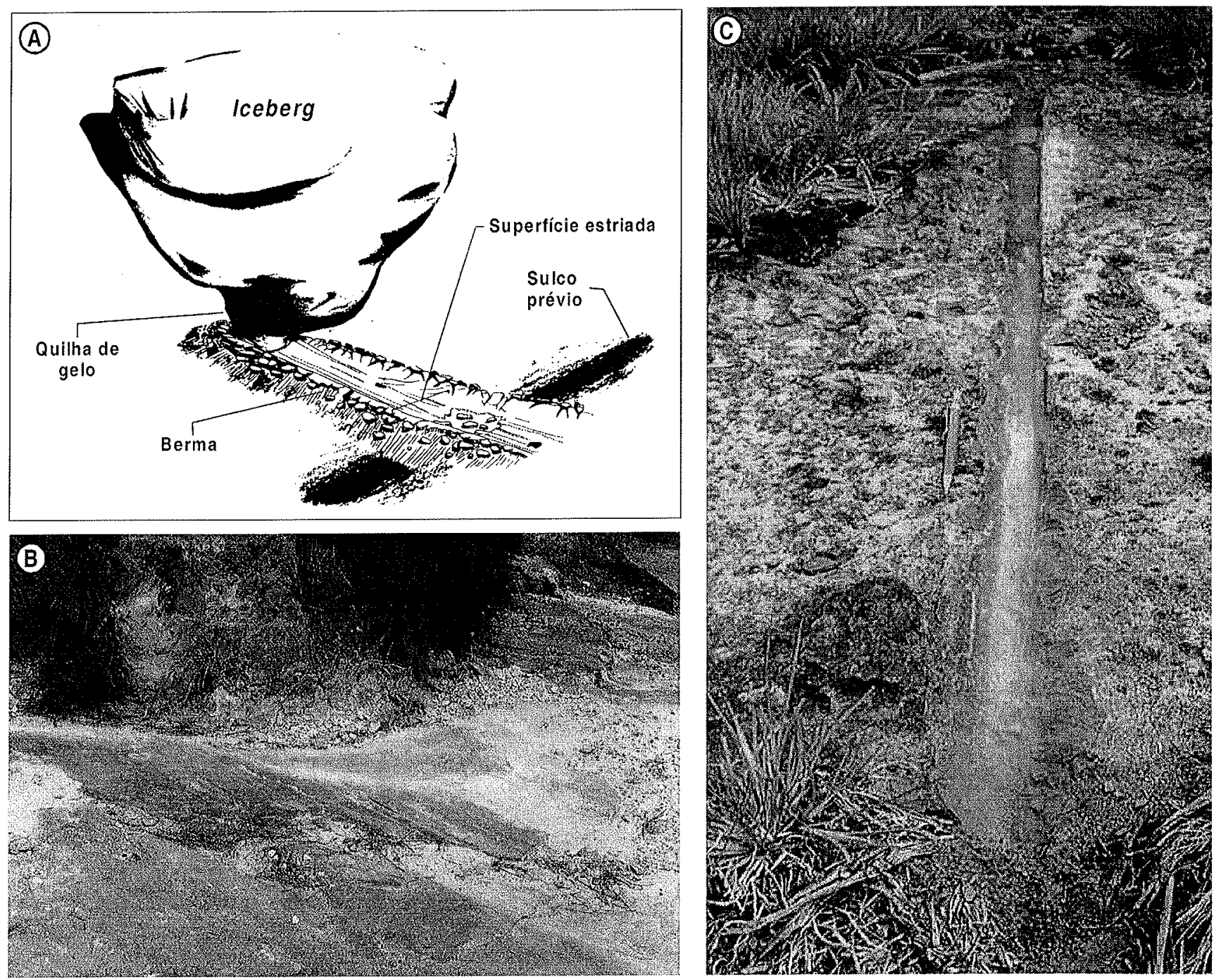

Figura 8-A) modelo proposto por Woodworth-Lynas \& Dowdeswell (1994) para a geração de superficies estriadas a partir de quilhas de icebergs; B) exemplo de superfície estriada descrita na área cuja descontinuidade lateral e a existência de bermas marginais permite analogia com o modelo ilustrado em $\mathrm{A} ; \mathrm{C}$ ) sulco isolado formado provavelmente pelo arraste de quilha de gelo flutuante.

pessura, que constitui o primeiro registro sedimentar do avanço de geleiras na área durante o Carbonífero. $\mathrm{Na}$ localidade de Witmarsum, situada um pouco a norte do rio do Salto, pode-se observar o contato do Tilito Cancela sobre os arenitos da Formação Furnas, em cujo topo existe um extenso pavimento estriado (Fuck et al. 1966, Bigarella et al. 1967), muito conhecido na comunidade geológica brasileira.

Os arenitos portadores de superfícies estriadas e sulcos, que jazem sobre os tilitos subglaciais, são interpretados como fácies de sistemas de leques subaquosos de outwash, depositados por correntes de água de degelo oriundas da geleira em recuo. Paleocorrentes medidas nos arenitos com estratificação cruzada (Fig. 3) indicam que as correntes de água de degelo fluiram preferencialmente para norte (azimute médio $1^{\circ}$ ).

A direção média (azimute $341^{\circ}$ ) das estrias e sulcos nos arenitos do vale do rio do Salto são coerentes com o sentido geral de avanço do gelo na Bacia do Paraná, que foi para NNW (ver indica- ções de paleofluxo na Tabela 1). Esta coincidência e a natureza dos arenitos sugerem proximidade com a zona de aterramento da geleira, mas sob plataforma de gelo flutuante (ice shelf). Neste caso, durante ciclos de avanço de menor magnitude, protuberâncias na base de geleiras podem gerar estrias e sulcos nos sedimentos de fundo, como ilustrado no modelo apresentado na figura 9. Mecanismo semelhante foi adotado por O'Brien \& Christie-Blick (1992) para interpretar feições de abrasão glacial intraformacionais em arenitos do Grupo Grant do Neopaleozóico australiano.

Não deve se descartar, entretanto, a possibilidade de que icebergs tenham atuado como agente formador dos pavimentos glaciais. Embora seja de se esperar grande desvio padrão na direção de estrias geradas pelo movimento de icebergs, uma vez que se movem ao sabor das correntes, em determinadas situações o seu movimento pode coincidir com o sentido do avanço das geleiras. Isto pode ocorrer quando do recuo de plataformas de gelo existentes em golfos ou mares epicontinentais, onde correntes de de- 


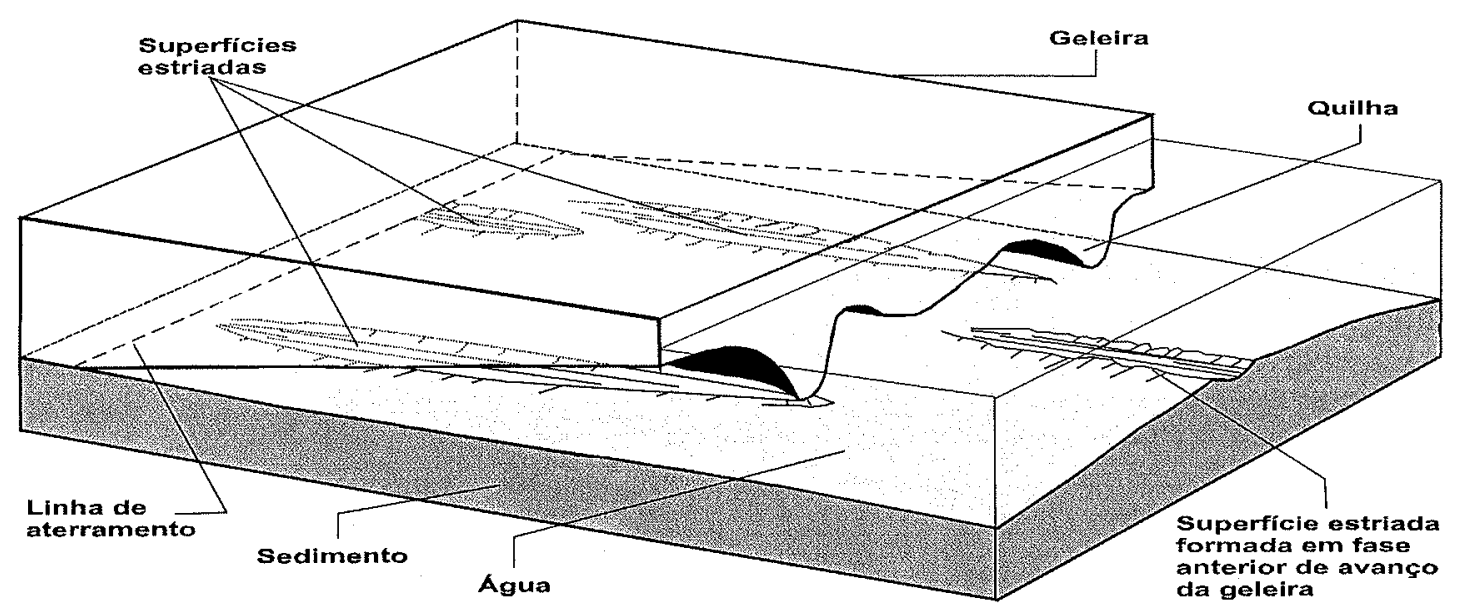

Figura 9 - Modelo proposto para explicar a origem de superficies estriadas a partir de plataforma de gelo flutuante.

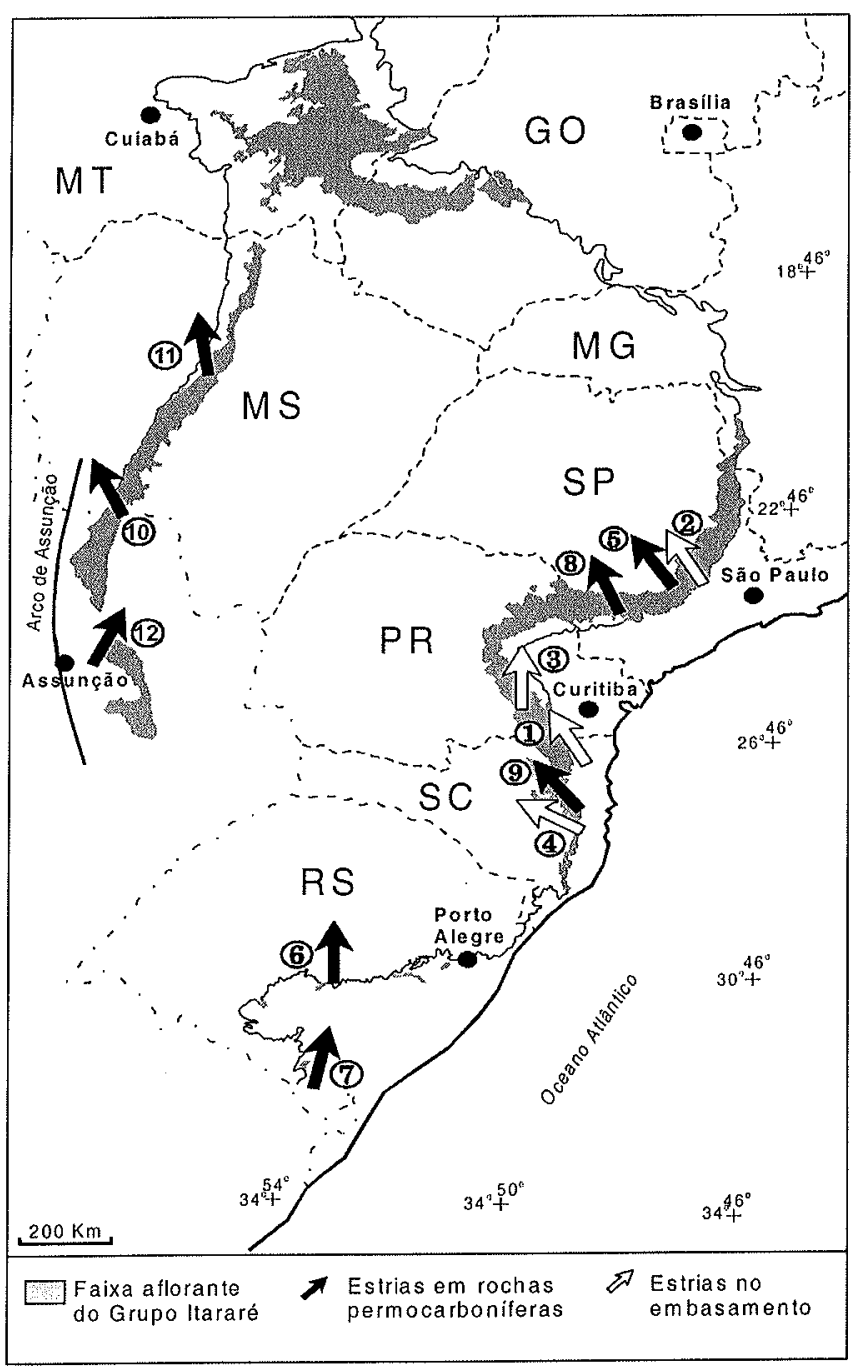

Figura 10-Principais ocorrências de estrias glaciais na Bacia do Paraná com suas respectivas orientações (números referemse às ocorrências listadas na tabela 1; modificado de Gesicki et al. 1996). gelo que emanam da base da geleira promovem o transporte dos icebergs liberados por fragmentação (calving).

Quer tenham sido geradas num ou noutro processo, a recorrência de estrias na vertical resultou da repetição alternada de eventos de avanço e recuo de geleira de base úmida, que gerou fácies de outwash sob a forma de lobos subaquosos.

Com o recuo generalizado da geleira para sul, houve migração lateral dos ambientes glaciais neste sentido, resultando numa sequiência de fácies de deglaciação. As fácies proximais de outwash foram desta maneira recobertas por sedimentos cada vez mais distais, tais como ritmitos com clastos caídos (dropstones) com intercalações de turbiditos de baixa densidade.

CONSWERAÇÕES FINAIS Pavimentos glaciais são de grande importância estratigráfica, pois registram eventos maiores de avanço de geleiras. No Permocarbonífero da Bacia do Paraná diversos indicadores apontam paleofluxo glacial regional para NNW (Fig. 10), a partir de uma calota polar localizada a SSE. Superfícies estriadas presentes na borda noroeste também indicam fluxo nesse sentido, sugerindo que as geleiras avançaram muitas centenas de quilômetros em determinados períodos de máximo glacial, cobrindo toda a Bacia do Paraná e ultrapassando, inclusive, sua margem noroeste (Gesicki et al. 1996, 2002)

A maior parte das superfícies estriadas encontradas estão em rochas do próprio Grupo Itararé, sobre diamictitos, ritmitos, conglomerados e arenitos, tendo sido geradas sobre os sedimentos no sítio deposicional. Estrias e sulcos, como as discutidas neste trabalho, são de grande importância paleogeográfica pois constituem evidência direta do avanço de geleiras sobre sistemas deposicionais ativos. Mais que isso, registram o avanço de plataformas de gelo flutuante na Bacia do Paraná durante a grande glaciação gondwânica permocarbonífera.

As superfícies estriadas descritas ocorrem em arenitos presentes na parte inferior de uma seqüência de fácies de deglaciação na base do Grupo Itararé. Outros intervalos semelhantes podem ocorrer em níveis estratigráficos mais altos porque, como observado por Vesely (2001) na região nordeste do Estado do Paraná, sucessões de fácies de deglaciação se repetem várias vezes no registro estratigráfico do Grupo Itararé, evidenciando o caráter cíclico dado pela alternância de fases de avanço e recuo de geleiras. 
Agradecimentos Os autores agradecem à FAPESP pelo apoio financeiro ao projeto "Análise de Paleocorrentes e Paleogeografia da Bacia do Paraná" (Proc.98/02183-3) e pela concessão de bolsa de mestrado ao primeiro autor (Proc.99/04559-3).

\section{Referências}

Almeida F.F.M. 1948. A "Roche Moutonnée" de Salto, Estado de São Paulo. Boletim Geologia e Metalurgia, 5: 112-118.

Assine, M. L. 1996. Aspectos da estratigrafia das sequiências précarboníferas da Bacia do Paraná no Brasil. São Paulo. 207 p. (Tese de Doutorado, Instituto de Geociências da Universidade de São Paulo).

Barbosa O. 1940. Estrias produzidas por gelo permi-carbonífero. Mineração e Metalurgia, 4:272-273.

Bigarella J.J., Salamuni R., Fuck R.A. 1967. Striated surfaces and related features developed by Gondwana ice sheets (State of Paraná, Brazil). Palaeogeo. Palaeoclim. Palaeoeco., 3:265-276.

Caetano-Chang M.R., Oliveira J.P., Brighetti J.M.P. 1990. Pavimento estriado em rochas do Subgrupo Itararé ao longo do Rio Piritubinha, sul do Estado de São Paulo, Rev. Bras. Geoc., 20:333-335.

Canuto J.R. 1985. Origem dos diamictitos e rochas associadas do Subgrupo Itararé, no sul do Estado do Paraná e norte do Estado de Santa Catarina. São Paulo. 187 p. (Dissertação de Mestrado, Instituto de Geociências da Universidade de São Paulo).

Carvalho P.F. 1940. Estrias glaciais em granodiorito sotoposto ao Gondwana de Santa Catarina. Mineração e Metalurgia, 4:271-272.

Dowdeswell J.A., Villinger H., Whittington R.J., Marienfeld P. 1993. Iceberg scouring in Scoresby Sund and on the East Greenland continental shelf. Marine Geol, 111:37-53.

França A.B. \& Potter P.E. 1988. Estratigrafia, ambiente deposicional e análise de reservatório do Grupo Itararé (Permocarbonífero), Bacia do Paraná (parte 1). Bol. Geoc. Petrobrás, 2:147-191.

França A.B., Winter W.R., Assine M.L. 1996. Arenitos Lapa-Vila Velha: um modelo de trato de sistemas subaquosos canal-lobos sob influência glacial, Grupo Itararé (C-P), Bacia do Paraná. Rev. Bras. Geoc., 26:43-56.

Fuck R.A. 1966. Nota explicativa da folha geológica de Quero-Quero. Boletim da Universidade Federal do Paraná (Geologia), 19:1-21.

Gesicki A.N., Riccomini C., Boggiani P.C., Coimbra A.M. 1996. Evidências de avanço glacial na Formação Aquidauana (Neopaleozóico da Bacia do Paraná) no Estado de Mato Grosso do Sul. In: SBG, Congr. Bras. Geol. 39, Salvador, Anais..., 1:124-127.

Gesicki A.L.D., Riccomini C., Boggiani P. C. 2002. Ice flow direction during late Paleozoic in western Paraná Basin, Brazil. J. Sou. Am. Ear: Sci., 14:933-939.

O'Brien P.E. \& Christic-Blick N. 1992. Glacially grooved surfaces in the Grant Group, Grant Range, Canning Basin and the extent of Late Palaeozoic Pilbara ice sheets. J. Austr. Geol. Geoph., 13:87-92.

Riccomini C. \& Velázquez V.F. 1999. Superfície estriada por geleira neopaleozóica no Paraguai Oriental. Rev. Bras. Geoc., 29:233-236

Rocha-Campos A.C., Machado L.C.R., Santos P.R., Canuto J.R., Castro J.C. 1988. Pavimento estriado da glaciação Neo-Paleozóica em Alfredo Wagner, SC, Brasil. Boletim IGUSP (Série Científica), 19:39-46.

Rocha-Campos A.C., Oliveira M.E.C.B., Santos P.R., Saad A.R. 1976. Boulder pavements and the sense of movement of late paleozoic glaciers in central eastern São Paulo State, Paraná Basin, Brazil. Boletim IGUSP, 7:149-160.

Rocha-Campos A.C., Santos P.R., Canuto J.R. 1999. Multiple, glacially striated, soft sediment surfaces in the Late Paleozoic and Proterozoic of Brazil. Anais Acad, Bras. Ciênc, 71:841.

Santos P.R., Rocha-Campos A.C., Canuto J.R. 1992. Estruturas de arrasto de icebergs em ritmitos do Subgrupo Itararé (Neo-Paleozóico), Trombudo Central, SC. Boletin IG-USP (Série Científica), 23:1-18.

Savage N. M. 1972. Soft-sediment glacial grooving of Dwyka age in South Africa. J. Sed. Petrol, 42:307-308.

Schneider R.L., Muhlmann H., Tommasi E., Medeiros R.A., Daemon R.A., Nogueira A.A. 1974. Revisão estratigráfica da Bacia do Paraná. In: SBG, Congr. Bras. Geol., 28, Porto Alegre, 1: 41-65.

Tomazelli L.J. \& Soliani E. 1982. Evidências de atividade glacial no Paleozóico Superior do Rio Grande do Sul, Brasil. In: SBG, Congr: Bras. Geol., 32, Salvador, Anais..., 4:1378-1391.

Vesely F.F. 2001. Análise de Seqüências em Sucessões Glaciais: Estudo de Caso no Grupo Itararé (C-P), Nordeste do Estado do Paraná. Rio Claro. 119 p. (Dissertação de Mestrado, Instituto de Geociências e Ciências Exatas da Universidade Estadual Paulista).

Vesely F.F. \& Assine M.L. 1998. Evidências de sedimentação subglacial na base do Grupo Itararé, Estado do Paraná. In: SBG, Congr. Bras. Geol., 40, Belo Horizonte, Anais..., 523.

Vesely F.F. \& Assine M.L. 1999. Superfícies estriadas pelo movimento de geleiras sobre substratos não-litificados: exemplos no Grupo Itararé, Estado do Paraná. In: SBGeologia/UNESP, Simp. Geol. Sudeste, 6, São Pedro, Boletim de Resumos..., 52.

Visser J.N.J, 1990. Glacial bedforms at the base of the PermoCarboniferous Dwyka Formation along the western margin of the Karoo Basin, South Africa. Sedimentology, 37:231-245.

Visser J.N.J. 1997. Deglaciation sequences in the Permo-carboniferous Karoo and Kalahari basins of southern Africa: a tool in the analysis os cyclic glaciomarine basin fills. Sedimentology, 44:507-522.

Weber J.N. 1958. Recent grooving in lake botton sediments at Great Slave Lake, Northwest Territories. J. Sed. Petrol, 28:333-341.

Woodworth-Lynas C.M.T. \& Dowdeswell J.D. 1994. Soft-sediment striated surfaces and massive diamiction facies produced by floating ice. In: M. Deynoux et al. (eds.) Earth's Glacial Record. Cambridge. Cambridge University Press. p. 241-259.

Woodworth-Lynas C.M.T. \& Guigné J.Y. 1990. Iceberg scours in the geological record: examples from glacial lake Agassiz. In: J.A. Dowdeswell \& J.D. Scourse (eds.) Glacimarine Enviroments: Processes and Sediments. London, Geological Society. p. 217-223.

Manuscrito A-1365 Recebido em

Revisão dos autores em 26 de dezembro de 2002 Revisão aceita em 28 de dezembro de 2002 